\title{
Evaluation of Mount Heaney leads slag to produce a cemented backfill
}

\author{
Ryan Veenstra North Queens/and Zinc/ Glencore Australia, Australia \\ Terrence Slattery North Queensland Zinc/ Glencore Australia, Australia \\ Claire Chauvier North Queensland Zinc/ Glencore Australia, Australia \\ Shaun van der Merwe North Queensland Zinc/ Glencore Australia, Australia
}

\begin{abstract}
Mount Heaney is a lead slag stockpile located between Mount Isa Copper Operations (MICO) and George Fisher Mine (GFM) in Mount Isa, Queensland, Australia. This slag pile contains relatively high zinc grades but due to its size is readily available for use as a partial fill material. As a result possible backfill cost savings exist; a study was conducted to determine the viability of using the slag as an additive for cemented paste backfill at GFM.
\end{abstract}

Two different methods for using the slag were examined in this paper. The first involved using it as a cement replacement in a blended binder. The second involved blending the slag with the tailings to create a cemented aggregate fill. This paper will present the process by which each method was conducted, and will present and discuss the results of the rheological and strength laboratory testing that was conducted on the materials. The paper will then present a financial analysis for the preferred method and will summarize what future work is still required. It is hoped that the results and analysis presented in this paper will give other mining operations a methodology to maximize their waste product usage.

\section{Introduction}

This paper summarizes the results from the laboratory testing program looking at how to include Mount Heaney slag in North Queensland Zinc's (NQZ) cemented paste backfill (CPB). This stockpile has been utilized since the early 1990s and is located north of Mount Isa Copper Operations (MICO), approximately $14 \mathrm{~km}$ south of GFM, adjacent to the haul road. It contains approximately $2 \mathrm{M} \mathrm{m}^{3}$ of slag ( $\left.\sim 4.5 \mathrm{Mt}\right)$.

Glencore's NQZ Division includes George Fisher Mine (GFM) and Lady Loretta Mine (LLM), which is located approximately $130 \mathrm{~km}$ north of Mount Isa in Queensland, Australia. Figure 1 shows the location of GFM and LLM in relation to Mount Isa, and the location of Mount Heaney.

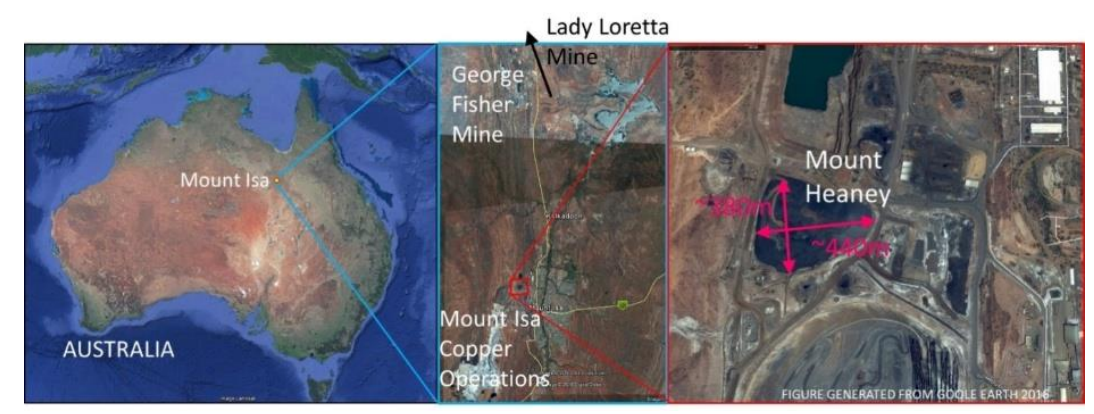


Both operations currently produce their cemented paste backfills (CPB) using the same harvested tails mined from Mount Isa Copper Operations (MICO) Tailings Dam 5. This harvesting operation was brought into production in 2005 to feed GFM. LLM commenced development in 2012 and first ore was produced in 2013. Both sites use their own respective water with GFM using a general purpose cement binder and LLM using a slag-blend binder.

\section{$2 \quad$ Mount Heaney slag}

Mount Heaney $(\mathrm{MH})$ slag was formed during the metallurgical process at the Mount Isa lead smelter. This slag has residual zinc but is uneconomic under current metal prices. Use of the slag would potentially drive the cost of paste fill down whilst diminishing the slag dump's footprint. Due to this, it was decided to explore alternate uses for $\mathrm{MH}$ slag.

Two methods for using $\mathrm{MH}$ slag were investigated: grinding it for use in a blended slag binder or unground as a blending aggregate in a cemented aggregate fill (CAF). MICO currently uses a ground lead slag (obtained from a different stockpile than Mount Heaney) to produce CPB with reduced cement content. Their ratio (according to the QC laboratory mix designs) is 60:40 ground $\mathrm{Pb}$ slag to general purpose (GP) cement.

\subsection{Mount Heaney properties}

The chemical composition of several MH slag samples were obtained using X-ray fluorescence (XRF). Note that XRF does not differentiate the types of oxides present. The average of these results are presented in Table 1. These results are compared to typical industry values for other commonly used pozzolanic binders. The MH slag does have some cementitious minerals (primarily low proportions of calcium, silicon, and aluminum oxides), but not as high as some of the other commonly used cementitious binders.

Table 1 Comparison of chemical analysis results between Mount Heaney slag and other cementatious materials

\begin{tabular}{cccccccc}
\hline Material & $\mathbf{A l}_{2} \mathbf{O}_{3}$ & $\mathbf{C a O}$ & $\mathbf{C u}$ & $\mathbf{F e}$ & $\mathbf{M g O}$ & $\mathbf{S}$ & $\mathbf{S i O}_{2}$ \\
\hline Mount Heaney Slag (XRF) & $3.14 \%$ & $23.50 \%$ & $0.03 \%$ & $22.90 \%$ & $1.22 \%$ & $1.54 \%$ & $18.80 \%$ \\
Portland Cement* & $6 \%$ & $63 \%$ & & & $2.50 \%$ & & $21 \%$ \\
Class F Flyash* & $23 \%$ & $23 \%$ & & & $4 \%$ & $52 \%$ \\
Class C Flyash* & $18 \%$ & $18 \%$ & & & $4.50 \%$ & & $35 \%$ \\
Blast Furnace Slag* & $10 \%$ & $39 \%$ & & & $10 \%$ & $1.40 \%$ & $35 \%$ \\
\hline
\end{tabular}

*Typical Industry Values

Samples from the surface of Mount Heaney were obtained. Figure 2 compares particle size distributions of $\mathrm{MH}$ slag (red) with harvested tails samples (green). The slag curves show a poorly graded and consistent material, with D50 of approximately $0.8 \mathrm{~mm}$. The specific gravity of slags was determined to be around 3.7. 


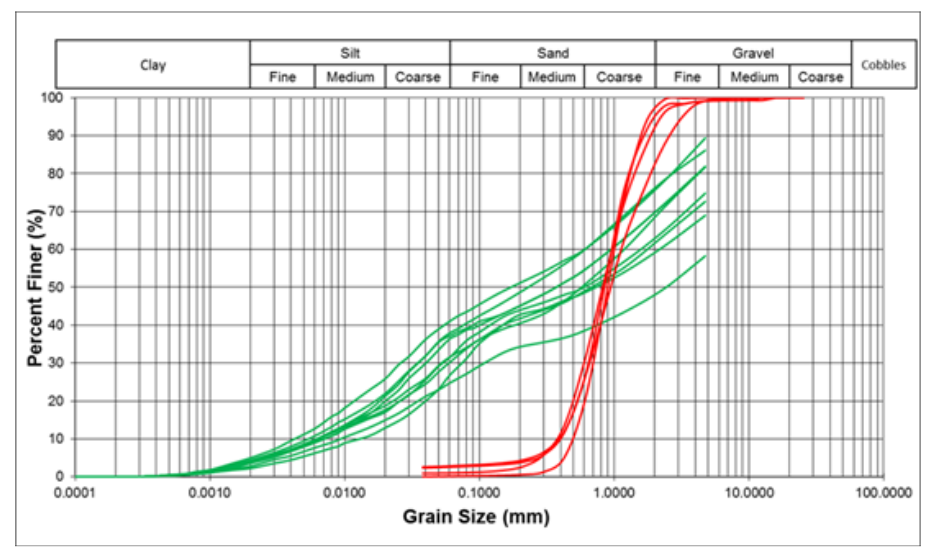

Figure 2 Particle size distributions for Mount Heaney Slag (red) and tailings harvested from TD5 (green)

\section{$3 \quad$ Blended binder results and discussion}

The laboratory testing of the blended binders consisted of unconfined compression strength (UCS) testing of CPB samples created using different blended binders. These blends included different slag grinds as well as three different activators (Sodium Silicate, hydrated lime, and GP cement). Trials using similar materials have been attempted previously (Cihangir et al., 2012; Williams, 2016)). A total of 23 blended binders were tested and are summarized in Table 2 . The samples were typically tested in triplicate at curing ages of 1, 3, 7, 14, and 28 days. Additional samples were cast for testing at longer curing ages if this proved necessary.

Table 2 Mix design combinations for blended binders

\begin{tabular}{|c|c|c|c|c|}
\hline Mix Number & Activator & Mill Type and Duration & Slag:Activator Ratio & Binder (\%) \\
\hline 1 & GP & 60 min. ball mill & $50: 50$ & 4 \\
\hline 2 & GP & 60 min. ball mill & $50: 50$ & 6 \\
\hline 3 & GP & None & $50: 50$ & 6 \\
\hline 4 & Sodium Silicate & 30 min. ball mill & $92: 8$ & 6 \\
\hline 5 & Sodium Silicate & 60 min. ball mill & $92: 8$ & 6 \\
\hline 6 & Sodium Silicate & 10 min. puck mill & 90:10 & 4 \\
\hline 7 & Sodium Silicate & 10 min. puck mill & $90: 10$ & 6 \\
\hline 8 & Sodium Silicate & 10 min. puck mill & $70: 30$ & 4 \\
\hline 9 & Sodium Silicate & 10 min. puck mill & $70: 30$ & 6 \\
\hline 10 & Hydrated Lime & 10 min. puck mill & $90: 10$ & 4 \\
\hline 11 & Hydrated Lime & 10 min. puck mill & $90: 10$ & 6 \\
\hline 12 & Hydrated Lime & 10 min. puck mill & $70: 30$ & 4 \\
\hline 13 & Hydrated Lime & 10 min. puck mill & $70: 30$ & 6 \\
\hline 14 & GP & 10 min. puck mill & $60: 40$ & 4 \\
\hline 15 & GP & 10 min. puck mill & $60: 40$ & 6 \\
\hline 16 & GP & 10 min. puck mill & $70: 30$ & 4 \\
\hline 17 & GP & 10 min. puck mill & $70: 30$ & 6 \\
\hline 18 & GP & 16 min. puck mill & $75: 25$ & 4 \\
\hline 19 & GP & 16 min. puck mill & $50: 50$ & 4 \\
\hline 20 & GP & 16 min. puck mill & $25: 75$ & 4 \\
\hline 21 & GP & 16 min. puck mill & $75: 25$ & 6 \\
\hline 22 & GP & 16 min. puck mill & $50: 50$ & 6 \\
\hline 23 & GP & 16 min. puck mill & $25: 75$ & 6 \\
\hline
\end{tabular}

Two grinding methods were used: a small ball mill and a 'dish and puck' mill. The ball mill was used to produce 
30 and 60 minute grinds. The puck mill was used to produce 10 and 16 minute grinds. The particle size of these grinds are shown in Figure 3, and are compared to particle size distributions for a typical GP, a typical ground blast furnace slag used by the cement industry, and the lead slag grind used by MICO.

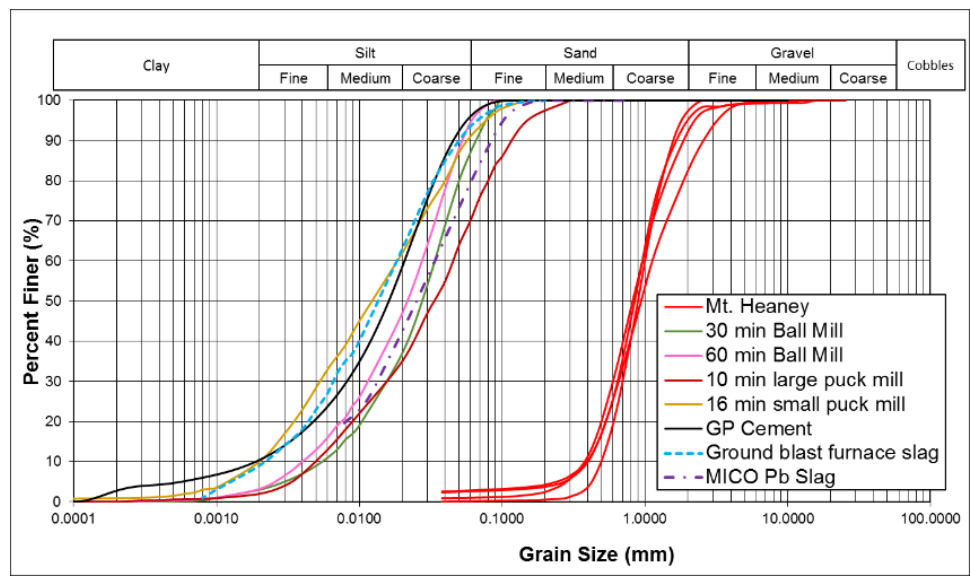

Figure 3 Comparison of particle size distributions for unground and ground Mount Heaney slag

The testing of the Sodium Silicate and hydrated lime blends showed that these samples, if they could be tested, did not generate any meaningful strength (i.e. were very similar to previously tested un-cemented or weakly cemented samples). There were some limited strength variations observed which were likely due to the mixes' differing mix densities.

The GP: slag blends all generated similar results to those observed in Figure 4. The solid lines trend the results from the control samples that were cast using $100 \%$ GP. The control samples were cast at the same time as the blended binder mixes.

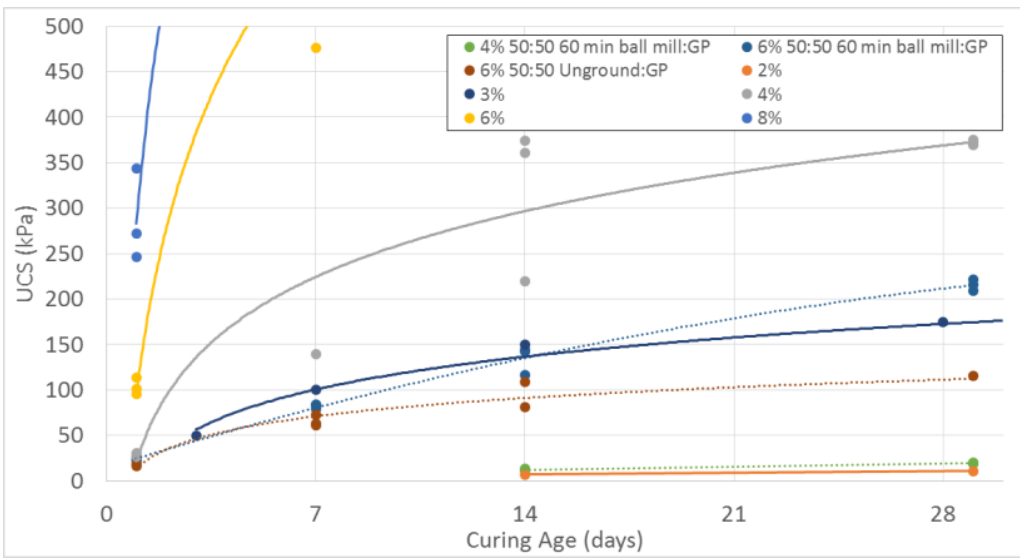

Figure 4 Comparison of strength gain curves from 100\% GP and slag blend binders

Both of the $6 \%$ blended binder samples had similar UCS results to that of the $3 \%$ control samples. This suggests that the slag within these blends are not helping the samples gain strength and that the strength difference observed are likely due to density and packing differences resulting from the differences in slag size. A similar trend was observed in all of the results regardless of the grind fineness.

These results show that ground MH slag tested is not suitable for use as a GP replacement. Possible reasons for this could be the age or oxidation level of the sample. Further work could be undertaken to determine if unexposed or fresher sections of Mount Heaney are suitable, but as slag is generally inert it is unlikely that this would be the case. It would also prove difficult to sort potentially useful slag from useless slag. A more productive course of action, if NQZ decides to continue pursuing a blended lead slag binder, would be to run a test program using the same lead slag that MICO uses to determine its suitability for CPB production at 


\section{$4 \quad$ Blended aggregate results and discussion}

This program involved testing five different mix designs which are summarized in Table 3. The slag was taken, unaltered, from the same samples that were used in the blended binder sample.

Table 3 Mix design combinations for blended aggregates

\begin{tabular}{ccc}
\hline Mix Number & Slag: Tails Ratio & Binder \% \\
\hline 1 & $66: 34$ & 6 \\
2 & $50: 50$ & 4 \\
3 & $50: 50$ & 6 \\
4 & $25: 75$ & 4 \\
5 & $25: 75$ & 6 \\
\hline
\end{tabular}

Figure 5 shows the particle size distributions for the MHS, the tailings used for the testing, and the $50: 50$ and 25:75 ratio curves. Also shown are the curves for the current upper and lower bound for unaltered tails, a typical processed tails, and the tails used in the casting after crushing. These results show that the addition of the $\mathrm{MH}$ slag to the tails produces a better graded material.

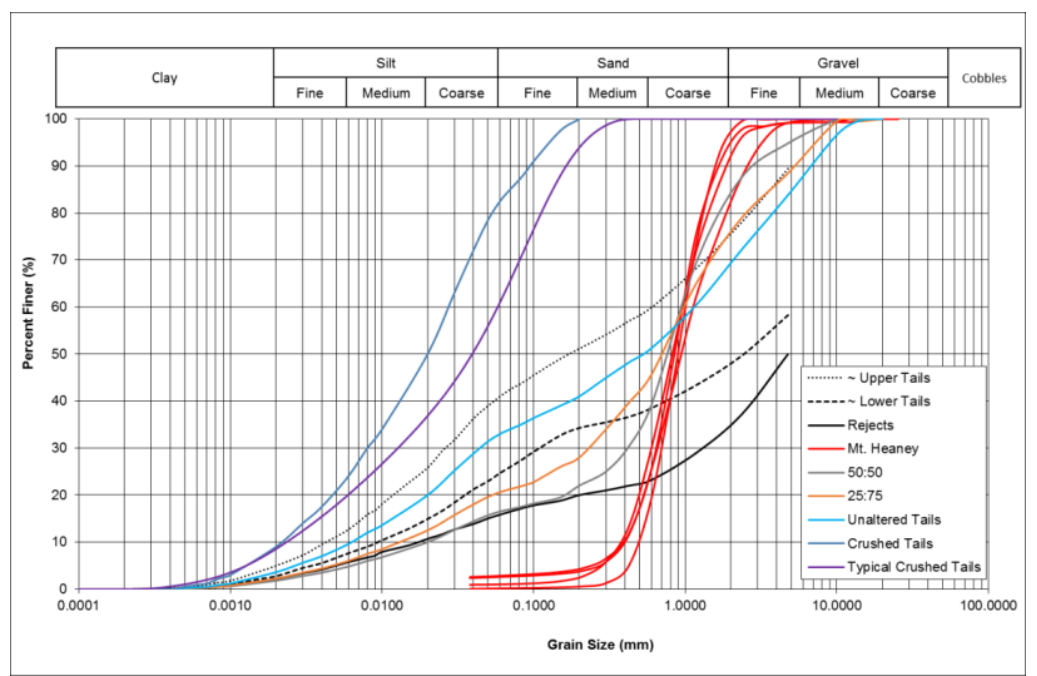

Figure 5 PSD curves showing how the addition of MH slag affects the CPB aggregate

Yield stress curves were determined for several of the mixes, using a desktop rheometer. These mixes were compared to a $100 \%$ tailings curve in Figure 6 . This showed that increases in $\mathrm{MH}$ slag cause the percent solids of the mix to increase for a given yield stress. This relationship is due to both the density of the MHS (SG $\approx 3.7$ ) and the coarsening of the mixes' PSDs. 


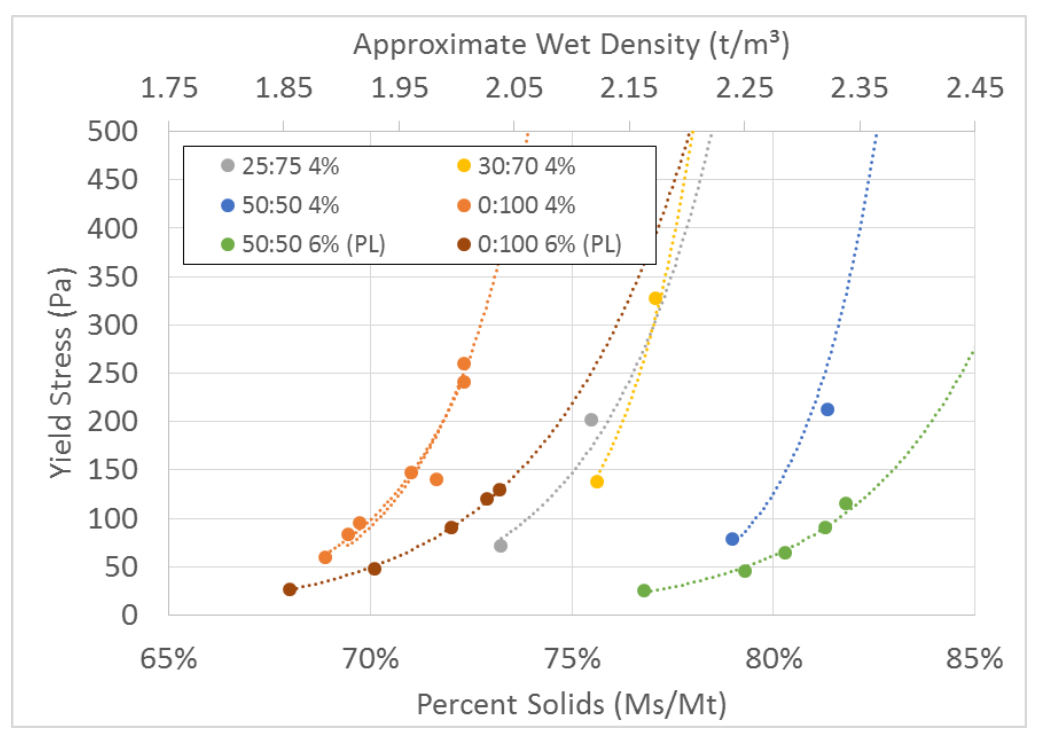

Figure 6 Yield stress curves for 100\% tailings and blended aggregate mixes.

Pipe loop testing of a 100\% tailings mix and a 50:50 mix were conducted at Weir Minerals Technical Centre in Port Melbourne (Weir, 2016). The yield stress results from this testing are also plotted on Figure 6 (denoted by PL). These results showed similar trends to those observed from the desktop rheometer tests, namely that the addition of slag caused the percent solids of the mix to increase. Note that the increase in percent solids also caused the yield stress of the material to increase slightly, but not enough to present issues for reticulating the CAF.

One trait of this type of backfill is that it has a tendency to settle at lower percent solids. Figure 7 is a photograph of a sample cast at approximately 75 percent solids which exhibited rapid settlement. GFM's CPB regularly exhibits some bleed water accumulation but not to the degree exhibited here. This sort of rapid settlement is usually observed in hydraulic fill. This means that tight control over a plant's production would be necessary to prevent segregation. The pipe loop testing suggested that the tested 50:50 mix settled at flow rates of less than $100 \mathrm{~m}^{3} / \mathrm{hr}$ and/or densities of less than $2.2 \mathrm{t} / \mathrm{m}^{3}$.

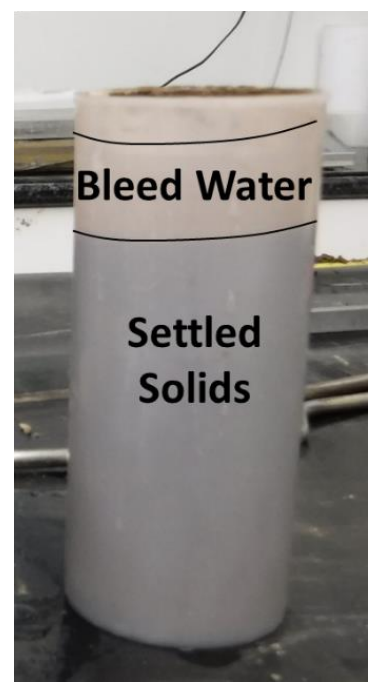

Figure 7 Bleed water segregation in a UCS sample cast at a low percent solids ( 75\%)

UCS samples were prepared for five mixes. The first was a trial mix cast at a $66: 34$ slag : tails mix at $6 \%$ binder. This mix was produced by creating the CPB mix first and then adding the slag to the mix. A $100 \%$ tailings control sample was cast at the same time. Both samples had yield stress values of approximately $80 \mathrm{~Pa}$ with corresponding wet densities of 2.3 and $1.9 \mathrm{t} / \mathrm{m}^{3}$, respectively. The results (Figure 7) show that the blended 
aggregate outperformed the control CPB by 100 and $200 \mathrm{kPa}$ after an approximately 28-day and 61-day cure respectively. Note that the blended aggregate mix did not exhibit large amounts of segregation.

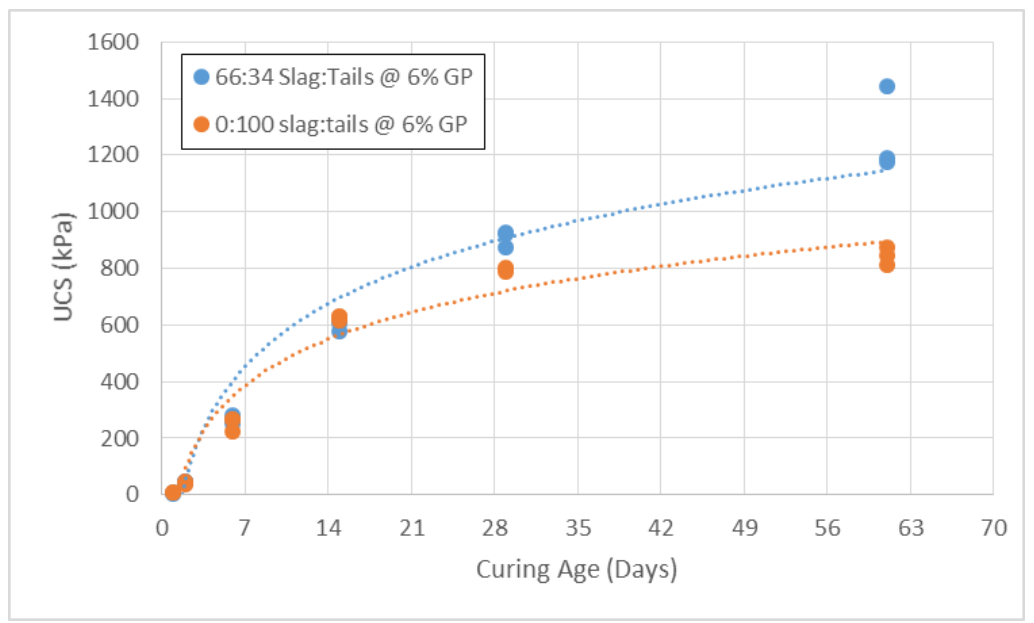

Figure 8 Comparison of UCS results from a $6 \%$ binder $66: 34$ slag : tails mix and a $6 \%$ binder $100 \%$ tailings control mix

Figure 8 show the UCS results from the four mixes made in a more traditional method where all materials were combined at the same time. This plot shows that increasing the amount of $\mathrm{MH}$ slag does increase the overall strength of the material. Note that these samples were cast at lower percent solids than the first mix in order to more closely represent the represent the CPB GFM was producing at the time. All four mixes exhibited some segregation No control samples were cast for comparison.

GFM usually generates 500 and $1000 \mathrm{kPa}$ UCS after a 28 -day cure using a 4 and $6 \%$ mix, respectively. These values are similar to the results seen in Figure 8 . This indicates that there is no decrease in strength observed due to the addition of the slag. However, additional laboratory testing would be required to determine if there is repeatable to and to quantify if there is any strength advantage from adding the slag.

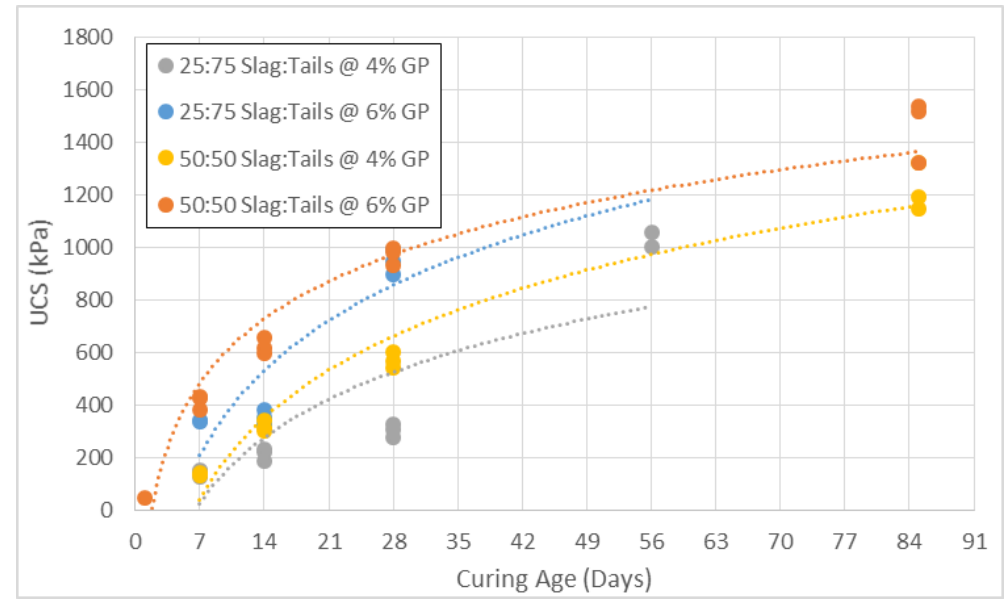

Figure 9 Comparison of UCS results from 4 blended aggregate mixes

A preliminary cost analysis of using $\mathrm{MH}$ slag identified that the initial costs savings are due to the decreased cost of mining $\mathrm{MH}$ slag versus harvesting tailings. It is estimated that a delivered tonne of $\mathrm{MH}$ slag costs a third less than a delivered tonne of harvested tails. This means a cost savings (assuming a 50:50 mix) of approximately $\$ 11,500$ per average GFM stope $\left(7000 \mathrm{~m}^{3}\right)$ or approximately $\$ 0.6 \mathrm{M}$ per year. If it is possible to decrease the CPB's cement content (due to the observed strength increase resulting from the use of a blended aggregate at higher blend ratios) then the cost savings could increase to approximately $\$ 20,500$ per stope or $\$ 1.0 \mathrm{M}$ year. However, as previously stated, more work is required to determine the amount of 
strength increase, the relationship between mix density and strength, minimum density required to retain the $\mathrm{MH}$ slag in suspension, etc.

Note that the incorporation of MH slag would require some rework to NQZ's paste plants in order produce the CAF. It would be ideal to able to vary the proportions of MH slag given a stope's type, location, mining method, etc. Again, the use of MH slag would require tight control over the mix.

\section{$5 \quad$ Conclusions and recommendations}

There is currently no indication that MH slag will be useful for producing a blended binder. If further work is desired than it is suggested that a sample of fresh slag (from the same source as where MICO receives their slag) be obtained and that this material be ground to a similar fineness as the 16-minute puck mill sample.

The initial blended CAF UCS results were positive with the CAF mixes meeting or surpassing the CPB UCS results. Some preliminary rheology work, including a pipe loop study, were conducted and suggest that the CAF could be delivered via a reticulation system. However, more work is required to determine the relationships between mix density, cement content, and strength.

\section{Acknowledgement}

The authors would like to thank GFM's management team for supporting the work involved with this project and the writing of this paper. They would also like to thank MICO's QC/Research laboratory and MIM Central Services for the use of their facilities to grind, classify, cast, and test the samples that generated the results presented in this paper.

\section{References}

Cihangir, F., Ercikdi, B., Kesimal, A., Turan, A., \& Deveci, H. 2012, 'Utilization of alki-activated blast furnace slag in paste backfill of highsulphide mill tailings: Effect of binder type and dosage', Minerals Engineering, vol. 30, pp. 33-43.

Weir M. 2016, 'Weir minerals report on the rheological characterization of george fisher mine tailings (Project \# 4063384-001)'. Port Melbourne: Weir Minerals Technical Centre.

Williams, K. 2016, 'Pastefill cost saving project', 5th North Queensland Geotechnical Workshop - Cost Savings Initiatives, Mount Isa Copper Operations, Mount Isa. 